\title{
Efeito do agente carreador na obtenção e caracterização do suco da laranja (citrus
}

\section{sinensis) por atomização}

\author{
Effect of the carrier agent on the obtaining and characterization of orange juice (citrus sinensis) by
} atomization

Efecto del agente transportador en la obtención y caracterización de zumo de naranja (citrus sinensis) por atomización

\section{Resumo}

A laranja (Citrus sinensis) é o fruto cítrico de origem asiática com sabor variando do doce ao levemente ácido e rico em ácido ascórbico (vitamina C), além de outros nutrientes sendo o Brasil o maior produtor mundial da fruta. A perecíbilidade pode ser contornada por meio de um secador spray dryer, que produz um pó padronizado e estável com facilidade de transporte e armazenamento. O presente estudo buscou analisar o efeito do uso de maltodextrina como agente carreador em diferentes concentrações e do uso de diferentes temperaturas do ar de entrada na obtenção do suco de laranja em pó através da secagem em spray dryer observando a conservação de suas propriedades físicoquímicas. Foram realizadas as analises físico-químicas com o pó produzido e com uma amostra comercial para comparação. O processo de secagem se mostrou viável com rendimentos em torno de $66 \%$, as propriedades do suco reidratado foram conservadas em sua maioria apresentando uma caracterização eficaz em relação ao produto similar comercial.

Palavras-chave: Spray dryer; Maltodextrina; Físico-química; Secagem; Conservação; Rendimento.

\begin{abstract}
The orange (Citrus sinensis) is the citrus fruit of Asian origin with flavor varying from sweet to slightly acidic and rich in ascorbic acid (vitamin C), in addition to other nutrients, Brazil being the world's largest producer of the fruit. Perishability can be circumvented by means of a spray dryer, which produces a standardized and stable powder with easy transport and storage. The present study sought to analyze the effect of the use of maltodextrin as a carrier agent in different concentrations and the use of different temperatures of the incoming air in obtaining powdered orange juice through spray drying, observing the conservation of its physical-chemical properties. Physical-chemical analyzes were performed with the powder produced and with a commercial sample for comparison. The drying process proved to be viable with yields around $66 \%$, the properties of the rehydrated juice were mostly preserved, presenting an effective characterization in relation to the similar commercial product.
\end{abstract}

Keywords: Spray dryer; Maltodextrin; Physicochemical; Drying; Conservation; Yield.

\section{Resumen}

La naranja (Citrus sinensis) es la fruta cítrica de origen asiático con un sabor que va de dulce a ligeramente ácido y rico en ácido ascórbico (vitamina C), además de otros nutrientes, siendo Brasil el mayor productor mundial de la fruta. La perecibilidad se puede evitar mediante un secador por pulverización, que produce un polvo estable y estandarizado con facilidad de transporte y almacenamiento. El presente estudio buscó analizar el efecto del uso de maltodextrina como agente portador en diferentes concentraciones y el uso de diferentes temperaturas del aire entrante en la obtención de jugo de naranja en polvo mediante secado por atomización, observando la conservación de sus propiedades físico-químicas. Los análisis físico-químicos se realizaron con el polvo producido y con una muestra 
comercial para comparación. El proceso de secado resultó viable con rendimientos en torno al $66 \%$, las propiedades del jugo rehidratado se conservaron en su mayoría, presentando una caracterización efectiva en relación con el producto comercial similar.

Palabras clave: Atomizador; Maltodextrina; Fisicoquímico; Secado; Conservación; Rendimiento.

\section{Introdução}

A laranja (Citrus sinensis) é uma das frutas mais consumida em todo mundo possui um bom gosto e ainda tem seu valor nutricional. Atualmente, a laranja é um alimento bastante presente na dieta de muitos devido ao fato de ser uma fonte barata de vitamina C. Ela é cultivada em áreas tropicais e subtropicais de todo o mundo, especialmente no Brasil e nos Estados Unidos, que juntos representam grande parte da produção mundial (Amaro \& Maia, 1997; Danieli et al., 2009).

A laranja é altamente perecível, por isso, vêm sendo comercializada no mercado in natura e em forma de sucos e polpas. A qualidade do suco de laranja é influenciada basicamente por fatores microbiológicos, enzimáticos, químicos e físicos, que comprometem suas características organolépticas (aroma, sabor, cor, consistência, estabilidade da turbidez, separação de fases sólido/líquido) e nutricionais (vitaminas). (Corrêa Neto \& Faria, 1999). Uma técnica de preservação interessante é a produção de suco em pó por meio da secagem em spray dryer ou atomização, onde obtém-se um produto com vida longa de prateleira, de alta estabilidade, além de apresentar uma redução do custo com relação a refrigeração (para as polpas), armazenamento, transporte e claro facilidade para importação/exportação. (Oliveira et al., 2007; Santos, et al., 2013; Rocha et al., 2014; Galvão et al., 2016).

A secagem em spray dryer pode ser utilizada para secagem de diversos produtos como sucos de frutas, polpa, ovo de avestruz, leite e extratos vegetais (Santos et al., 2013; Rocha et al., 2014; Aquino et al., 2014; Perrone et al., 2013 e Vasconcelos et al., 2005). Essa técnica consiste em uma pulverização de um produto em uma câmara onde passa uma corrente de ar quente de maneira que o solvente, geralmente a água, é evaporado, separando os sólidos solúveis existentes, com uma degradação mínima obtendo um produto em pó (Gava, 1998; Fioreze, 2003).

No entanto esta tecnologia oferece problemas, devido os sucos de frutas apresentarem alta concentração de açúcar, este processo de pulverização resulta em pós com baixa temperatura de transição vítrea, pegajosidade (stickness) e alta higroscopicidade, que vai ocasionar uma aderência nas paredes do secador, acumulando os pós e dificultando o manuseio (Fazaeli et al., 2012). Com a adição de agentes carreadores ao processo de secagem em spray dryer como: amidos, algumas gomas, lipídeos e proteínas ao suco de fruta acarreta um aumenta da temperatura de transição vítrea do pó formado, reduzindo o acúmulo dos pós nas paredes, consequentemente aumenta o rendimento do processo e melhora na conservação do produto em condições ambientais, devido à formação de uma camada protetora (Bhandari et al., 1997; Phisut, 2012; Oliveira et al., 2013; Muzaffar et al., 2015). No caso dos sucos de frutas, os agentes mais comumente utilizados têm sido as maltodextrinas por sua cor e sabor neutro além de seu baixo custo comparado a outros agentes carreadores. (Bhandari et al., 1997; Adhikari et al., 2004; Phisut, 2012). No estudo da secagem com diferentes agentes carreadores no extrato de yacon (Smallanthus sonchifolius) por spray dryer, foi observado que dentre os agentes carreadores pesquisados a maltodextrina indicou que foi possível obter extrato seco de yacon, com bom rendimento e baixa retenção de material na parede da câmara de secagem (Asquieri et al., 2020).

Dentre as variáveis estudadas durante a secagem em spray dryer temos a pressão, a vazão e a temperatura de entrada do ar. Nesse processo a temperatura de entrada do ar de secagem é uma variável de grande importância para o produto obtido, ela pode afetar as propriedades do pó como o teor de umidade, atividade de água, a densidade, tamanho de partícula, higroscopicidade e morfologia. (Gupta, 1978; Goula \& Adamopoulos, 2003; Tonon et al., 2009).

Dessa forma, o objetivo do presente estudo foi analisar a influência da concentração de maltodextrina e a temperatura de entrada do ar no processo de secagem do suco de laranja através da técnica em spray dryer e realizar uma caracterização 
físico-química a fim de estudar a viabilidade desse processo observando a conservação de características físico químicas do suco ao longo do processo e sua comparação com produtos já comerciais.

\section{Metodologia}

A metodologia utilizada foi baseada no método quantitativo, os dados foram coletados por meio de metodologias e por aplicações de equações que geraram resultados que foram analisados estatisticamente (Pereira et al., 2018).

\subsection{Material}

As laranjas utilizadas para obtenção do suco a ser seco em spray dryer foram do tipo pêra (Citrus sinensis L. Osbeck) e compradas na EMPASA. O agente carreador utilizado foi a maltodextrina da marca Athletica Nutrition, sem sabor, adquirida na loja de suplementos para atletas VitaBrasilnet. O suco em pó, usado como referência comercial, sabor laranja foi adquirido no Supermercado Manaíra. Todo o material foi adquirido na cidade de João Pessoa- PB, Brasil.

\subsection{Métodos}

\subsubsection{Preparo da amostra}

As laranjas foram cortadas ao meio e espremidas em um espremedor de laranja elétrico modelo Turbo Citrus da marca Mondial para obter-se o suco em seguida passado em peneira de \#16 de forma a eliminar os gomos da laranja. Foi adicionado ao suco a maltodextrina em 3 diferentes concentrações:15, 20 e 25\% em massa a concentração de maltodextrina foi fundamentada no estudo de (Cavalcante et al., 2017; Mendoza-Corvis et al., 2016) e agitado a uma velocidade de $2000 \mathrm{rpm}$ em um agitador mecânico Fisatom modelo 713D até dissolução completa.

\subsubsection{Secagem}

A secagem foi realizada em um spray dryer de escala piloto modelo LM - SD 5.0. da LabMaq Brasil, com uma vazão de alimentação de $1,5 \mathrm{~L} / \mathrm{h}$, vazão do soprador de $2,8 \mathrm{~m}^{3} / \mathrm{min}$, uma pressão de $500 \mathrm{kPa}$, vazão do pulverizador de ar comprimido $2100 \mathrm{~L} / \mathrm{h}$ e nas diferentes temperaturas de entrada do ar de 140,150 e $160^{\circ} \mathrm{C}$. A temperatura foi baseada em estudos anteriores de (Perrone et al., 2013; Mendoza-Corvis et al., 2016 e Cavalcante et al., 2017). O material obtido após a secagem foi estocado em sacos plásticos vedados com fita adesiva e etiquetados. Os sacos plásticos foram envoltos de papel alumínio, condicionados em potes de vidro com tampa para sua conservação até análises posteriores.

O rendimento do processo foi obtido pela razão entre a massa de pó obtida após a secagem e a massa de sólidos presentes no suco de laranja obtido pelo teor de sólidos totais juntamente com a maltodextrina adicionada.

\subsection{Análises físico-químicas}

As análises de sólidos totais, ${ }^{\circ} \mathrm{Brix}, \mathrm{pH}$, atividade de água, umidade e teor de ácido ascórbico (vitamina C) e foram realizadas em triplicata a fim de aplicar nos resultados obtidos o teste tukey, com nível de confiança de 95\%.

O Teor de sólidos totais foi realizado no suco in natura segundo a metodologia do Instituto Adolfo Lutz (2008), em uma estufa do modelo SL-100 da marca Solab, Brasil.

Para medir os sólidos solúveis dos sucos em pó foram preparados dois tipos de amostras. As primeiras amostras foram adicionadas $9 \mathrm{ml}$ de água destilada a $1 \mathrm{~g}$ de suco em pó, homogeneizadas e logo em seguida foram realizadas as leituras dos ${ }^{\circ}$ Brix e os resultados foram multiplicados por dez, devido á diluição, segundo a metodologia (Instituto Adolfo Lutz, 1985). Na segunda amostra os sucos em pó foram reidratados, fez-se a reidratação para obter o teor de sólidos do suco in natura $(8,5 \%)$ com a maltodextrina adicionada (8,5\% acrescido de 15, 20 e 25\%) que consistem de 23,41; 28,51 e 33,51\% de sólidos e 76,59; 
71,49 e 66,49 \% de água, respectivamente. Preparados os sucos e homogeneizados foram determinadas as medições de ${ }^{\circ}$ Brix e os pH que foram realizadas com o uso de um Refratômetro Abbe digital de bancada marca Nova WYA-2S, Brasil e pHmetro da marca Analyser do modelo pH 300/ Brasil, respectivamente. Também foram determinadas as concentrações dos sólidos solúveis do suco in natura e suco in natura com adição de maltodextrina (15, 20 e 25\%).

A atividade de água foi medida com através de um equipamento Novasina LabMaster AW, com precisão de +/- 0,003, Suíça.

A Umidade realizada segundo a metodologia do Instituto Adolfo Lutz (2008), pelo método gravimétrico em estufa a vácuo modelo 6002 marca Hot pack a $70^{\circ} \mathrm{C}$ e uma pressão menor que $75 \mathrm{mmHg}$ até peso constante.

O Teor de ácido ascórbico foi determinado através do método titulométrico baseado na redução do indicador 2,6diclorofenolindofenol pelo ácido ascórbico em que os resultados foram expressos em mg de ácido ascórbico por $100 \mathrm{~g}$ de amostra (Instituto Adolfo Lutz, 2008).

A Granulometria foi realizada com uso do equipamento marca CILAS 1090LD/França, onde operando em modo seco, os pós foram dispersos através de vibração mecânica sobre jato de ar comprimido com 2500 mb de pressão. A dispersão tem período de $15 \mathrm{~s}$. Após a dispersão, a coleta de dados dura $5 \mathrm{~s}$. A análise via seca, possui faixa de medição de 0,1 até 500 micrómetros.

A microscopia eletrônica de varredura (MEV) o material a ser analisado, foi disposto sobre o suporte coberto com a fita de carbono através da técnica do esfregaço. As amostras foram metalizadas uma corrente de $25 \mathrm{~mA}$ por 3 minutos - com camada aproximada de $24 \mathrm{~nm}$ com ouro. O equipamento utilizado foi da marca LEO 1430/Alemanha.

\section{Resultados e Discussão}

A Tabela 1 mostra o rendimento do suco em pó da laranja obtido em spray dryer nas concentrações de maltodextrina de 15 a $25 \%$ e temperatura do ar de secagem de 140 a $150^{\circ} \mathrm{C}$. É possível observar que a condição de secagem que gerou o melhor rendimento foi a realizada com $20 \%$ de maltodextrina adicionada com a temperatura variando de 140 a $150^{\circ} \mathrm{C}$. Esses valores se mostraram elevados ao comparar com o resultado de (Chegini \& Ghobadian, 2007) que obtiveram rendimentos de 18 a $35 \%$ na secagem de suco de laranja com maltodextrina nas temperaturas de entrada do ar de 140,150 e $160^{\circ} \mathrm{C}$. O aumento da temperatura promoveu de maneira geral, uma pequena diminuição do rendimento, este comportamento pode ser explicado pela possível fusão das partículas de pó em altas temperaturas fato observado também por (Chegini \& Ghobadian, 2007). 
Tabela 1. Rendimento obtido após a secagem dos sucos da laranja em pó nas diferentes condições.

\begin{tabular}{ccc}
\hline Concentração de maltodextrina (\%) & Temperatura do ar de secagem $\left({ }^{\circ} \mathbf{C}\right)$ & Rendimento $(\%)$ \\
\hline 15 & 140 & $64,08^{(\mathrm{a}, \mathrm{b}) ;(\mathrm{a})}$ \\
15 & 150 & $64,15^{(\mathrm{a}, \mathrm{b}) ;(\mathrm{a})}$ \\
15 & 160 & $' 61,80^{(\mathrm{a}, \mathrm{b}) ;(\mathrm{a})}$ \\
20 & 140 & $66,95^{(\mathrm{a}) ;(\mathrm{a})}$ \\
20 & 150 & $66,90^{(\mathrm{a}) ;(\mathrm{a})}$ \\
20 & 160 & $62,16^{(\mathrm{a}) ;(\mathrm{a})}$ \\
25 & 140 & $60,71^{(\mathrm{b}) ;(\mathrm{a})}$ \\
25 & 150 & $59,51^{(\mathrm{b}) ;(\mathrm{a})}$ \\
25 & 160 & $59,83^{(\mathrm{b}) ;(\mathrm{a})}$ \\
\hline
\end{tabular}

* Médias seguidas por mesma letra, na primeira coluna, refere-se ao efeito da concentração (independente da temperatura) e na segunda coluna refere-se a temperatura (independente da concentração) não diferem estatisticamente entre si (p>0,05) pelo teste de Tukey. Fonte: Autores (2021).

De acordo com os resultados estatísticos apresentados na Tabela 1, observa-se que a variação da concentração de maltodextrina de 15 para $25 \%$ independente da temperatura não modifica o rendimento do processo (p>0,05), entretanto a variação de concentração de 20 para $25 \%$ modifica sim o rendimento $(\mathrm{p} \leq 0,05)$. Com relação ao aumento da temperatura de entrada do ar de secagem de 140,150 e $160^{\circ} \mathrm{C}$ independente da concentração de maltodextrina não houve diferença (p>0,05) sendo as variáveis praticamente indiferentes ao rendimento do processo.

\subsection{Propriedades físico-químicas}

A Tabela 2 mostra o teor de sólidos solúveis ( ${ }^{\circ}$ Brix), $\mathrm{pH}$ e teor de ácido ascórbico (vitamina $\mathrm{C}$ ) dos sucos antes do processo de secagem: in natura e in natura com adição da maltodextrina nos teores de 15, 20 e 25\%. Como esperado, após a adição do percentual de maltodextrina os sólidos solúveis aumentaram em comparação com a amostra do suco in natura. A utilização destas determinações do ${ }^{\circ}$ Brix, $\mathrm{pH}$ e vitamina $\mathrm{C}$ foram utilizados como parâmetros para comparação destas propriedades físico- químicas com as dos pós após secagem.

Tabela 2. Propriedades físico-químicas dos sucos in natura e in natura com maltodextrina antes da secagem.

\begin{tabular}{lccc}
\hline Suco antes da secagem & ${ }^{\circ}$ Brix & pH & Vitamina C \\
\hline In natura & $6,800 \pm 0,100$ & $3,730 \pm 0,020$ & $40,943 \pm 3,346$ \\
In natura com 15\% maltodextrina & $19,966 \pm 0,208$ & $3,683 \pm 0,025$ & - \\
In natura com 20\% maltodextrina & $22,800 \pm 0,173$ & $3,783 \pm 0,015$ & - \\
In natura com 25\% maltodextrina & $25,266 \pm 0,152$ & $3,753 \pm 0,020$ & - \\
\hline
\end{tabular}

Nota. Vitamina C (mg de ácido ascórbico/100g de suco)

Fonte: Autores (2021).

Na Tabela 2 o resultado do pH praticamente não foram alterados com a adição da maltodextrina, resultados que já são esperados, já que a maltodextrina não tem componentes ácidos em sua composição. Segundo os autores (Santos et al., 2014) foi observado para a polpa de goiaba integral o $\mathrm{pH}$ foi de 3,76 e por (Sugai et al., 2002) que obtiveram $\mathrm{pH}$ de 3,75 e 3,85 respectivamente para a laranja-pera. 
A Tabela 2 mostra que a quantidade de vitamina $C$ do suco de laranja in natura medida foi de 40,943 $\pm 3,346 \mathrm{mg}$ de ácido ascórbico/100g de suco. A vitamina $\mathrm{C}$ do suco com maltodextrina não foi determinada, pois a sua adição não alteraria seu resultado sabendo que em sua composição não ha vitamina C. Esse valor se mostrou um pouco abaixo do obtido por (Couto \& Canniatti-brazaca, 2010) e superior ao obtido por (Danieli et al., 2009), já (Cunha et al., 2014) obteve um teor de ácido ascórbico de $34,87 \mathrm{mg} / 100 \mathrm{ml}$. No entanto as propriedades de uma fruta podem ser alteradas dependendo da safra, da época do ano, da região entre outros fatores.

A determinação de sólidos solúveis foi realizada para avaliar o teor de maltodextrina necessário em secagem em spray dryer, considerando o mínimo necessário para a secagem em spray dryer é de $22 \%$ de sólidos totais. O suco de laranja in natura apresentou um teor médio de sólidos solúveis de 8,510\% $\pm 0,0360$ e a partir desse resultado fixou-se uma concentração mínima de maltodextrina a ser adicionada ao suco de $15 \%$ em massa. Oliveira et al. (2006) encontrou um teor de sólidos totais de 6,93\%, para a polpa de pitanga integral e formulada com $15 \%$ de maltodextrina. Oliveira et al. (2013) estudaram a estabilidade da polpa de morango atomizada utilizando diferentes agentes carreadores, os sólidos totais para a polpa de morango foi de $6,79 \%$, o que justifica a adição de agente carreador antes da secagem por atomização, evitando problemas de aderência e pegajosidade, tanto nas paredes do secador como no produto final. 
Tabela 3. Resultados da caracterização físico-química dos pós obtidos após o processo de secagem nas diferentes temperaturas e concentrações de maltodextrina.

\begin{tabular}{|c|c|c|c|}
\hline $15 \%$ de Maltodextrina & $140\left({ }^{\circ} \mathrm{C}\right)$ & $150\left({ }^{\circ} \mathrm{C}\right)$ & $160\left({ }^{\circ} \mathrm{C}\right)$ \\
\hline${ }^{\circ}$ Brix do suco em pó & $86,666 \pm 1,154^{a}$ & $84,333 \pm 0,577^{\mathrm{a}}$ & $85,666 \pm 1,154^{\mathrm{a}}$ \\
\hline${ }^{\circ}$ Brix reidratado & $19,133 \pm 0,115^{\mathrm{a}}$ & $19,500 \pm 0,200^{\mathrm{a}}$ & $19,433 \pm 0,230^{\mathrm{a}}$ \\
\hline Atividade de água & $0,284 \pm 0,012^{\mathrm{a}}$ & $0,259 \pm 0,005^{\mathrm{a}, \mathrm{c}}$ & $0,216 \pm 0,013^{b}$ \\
\hline Umidade (\%) & $2,477 \pm 0,524^{\mathrm{a}}$ & $2,179 \pm 0,761^{\mathrm{a}}$ & $2,143 \pm 0,169^{a}$ \\
\hline Vitamin C (mg de vitamina $\mathrm{C} / 100 \mathrm{~g})$ & $29,413 \pm 0,695^{\mathrm{a}}$ & $31,896 \pm 1,243^{\mathrm{a}}$ & $30,783 \pm 2,809^{a}$ \\
\hline $\mathrm{pH}$ & $3,683 \pm 0,015^{\mathrm{a}}$ & $3,643 \pm 0,032^{\mathrm{a}}$ & $3,686 \pm 0,015^{\mathrm{a}}$ \\
\hline $20 \%$ de Maltodextrina & $140\left({ }^{\circ} \mathrm{C}\right)$ & $150\left({ }^{\circ} \mathrm{C}\right)$ & $160\left({ }^{\circ} \mathrm{C}\right)$ \\
\hline${ }^{\circ}$ Brix do suco em pó & $89,000 \pm 1,732^{\mathrm{a}}$ & $87,333 \pm 1,154^{\mathrm{a}}$ & $88,000 \pm 0,000^{\mathrm{a}}$ \\
\hline${ }^{\circ}$ Brix reidratado & $21,933 \pm 0,757^{\mathrm{a}}$ & $22,566 \pm 0,115^{\mathrm{a}}$ & $21,866 \pm 0,152^{\mathrm{a}}$ \\
\hline Atividade de água & $0,297 \pm 0,022^{\mathrm{a}}$ & $0,296 \pm 0,002^{\mathrm{a}}$ & $0,295 \pm 0,011^{\mathrm{a}}$ \\
\hline Umidade (\%) & $2,251 \pm 0,367^{\mathrm{a}}$ & $2,107 \pm 0,816^{\mathrm{a}}$ & $1,935 \pm 0,242^{\mathrm{a}}$ \\
\hline Vitamin C (mg de vitamina $\mathrm{C} / 100 \mathrm{~g})$ & $28,546 \pm 1,897^{\mathrm{a}}$ & $28,326 \pm 1,443^{\mathrm{a}}$ & $29,383 \pm 2,188^{\mathrm{a}}$ \\
\hline $\mathrm{pH}$ & $3,773 \pm 0,037^{\mathrm{a}}$ & $3,786 \pm 0,011^{\mathrm{a}}$ & $3,763 \pm 0,015^{\mathrm{a}}$ \\
\hline $25 \%$ de Maltodextrina & $140\left({ }^{\circ} \mathrm{C}\right)$ & $150\left({ }^{\circ} \mathrm{C}\right)$ & $160\left({ }^{\circ} \mathrm{C}\right)$ \\
\hline${ }^{\circ}$ Brix do suco em pó & $92,400 \pm 0,000^{\mathrm{a}}$ & $92,666 \pm 0,577^{\mathrm{a}}$ & $92,666 \pm 1,154^{\mathrm{a}}$ \\
\hline${ }^{\circ}$ Brix reidratado & $25,466 \pm 0,230^{\mathrm{a}}$ & $25,166 \pm 0,450^{\mathrm{a}}$ & $25,000 \pm 0,200^{\mathrm{a}}$ \\
\hline Atividade de água & $0,275 \pm 0,0149^{\mathrm{a}}$ & $0,270 \pm 0,015^{\mathrm{a}}$ & $0,261 \pm 0,026^{\mathrm{a}}$ \\
\hline idade $(\%)$ & $1,925 \pm 0,809^{\mathrm{a}}$ & $1,704 \pm 0,5862^{\mathrm{a}}$ & $1,557 \pm 0,291^{\mathrm{a}}$ \\
\hline Vitamin C (mg de vitamina $\mathrm{C} / 100 \mathrm{~g}$ & $31,473 \pm 1,398^{\mathrm{a}}$ & $29,000 \pm 3,372^{\mathrm{a}}$ & $29,463 \pm 2,113^{\mathrm{a}}$ \\
\hline $\mathrm{pH}$ & $3,786 \pm 0,030^{\mathrm{a}}$ & $3,800 \pm 0,020^{\mathrm{a}}$ & $3,816 \pm 0,020^{\mathrm{a}}$ \\
\hline
\end{tabular}

* Médias seguidas por mesma letra, na mesma linha, não diferem estatisticamente entre si (p>0,05) pelo teste de Tukey. Fonte: Autores (2021).

A Tabela 3 mostra os sólidos solúveis do suco em pó nas diferentes temperaturas do ar de secagem e concentrações de

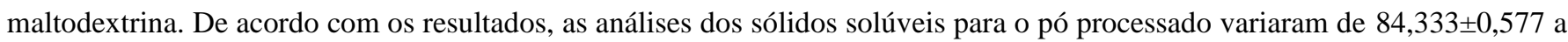


$92,666 \pm 1,154$. Com relação às diferentes temperaturas de entrada do ar utilizadas, fixando as concentrações de maltodextrina, observa-se que essa variável não teve efeito nos sólidos solúveis dos pós obtidos, nota-se um esperado aumento dos sólidos solúveis, devido ao aumento da concentração de maltodextrina. Analisando estatisticamente, em relação ao aumento da temperatura de 140 para $160^{\circ} \mathrm{C}$, para as concentrações de maltodextrina utilizadas não houve diferença estatística $(p>0,05)$ no teor de sólidos solúveis.

As medidas dos sólidos solúveis para os sucos em pó da laranja são próximas ao observado na secagem por atomização do suco integral de caju por Rocha et al. (2014), que obteve um ${ }^{\circ}$ Brix de 98,67 e para o suco da goiaba em pó, obtido por spray dryer a temperatura de $120^{\circ} \mathrm{C}$ com adição de $10 \%$ de maltodextrina, o ${ }^{\circ}$ Brix foi de 93,00 a $\pm 0,26$ segundo os autores (Santos et al., 2014).

Ao comparar os resultados dos sólidos solúveis do suco em pó da Tabela 3 com o suco comercial em pó da Tabela 4, esses valores se mostram bem próximos. As medidas dos sólidos solúveis para o suco em pó obtido e para o suco comercial são próximas ao observada na literatura (Santos et al., 2013; Rocha et al., 2014).

Tabela 4. Resultados da caracterização físico-química do suco comercial em pó.

\begin{tabular}{lc}
\hline \multicolumn{2}{c}{ Suco comercial em pó } \\
\hline${ }^{\circ}$ Brix do suco em pó & $94,333 \pm 1,528$ \\
${ }^{\circ}$ Brix reidratado & $2,433 \pm 0,057$ \\
Atividade de água & $0,484 \pm 0,003$ \\
Umidade (\%) & $0,182 \pm 0,028$ \\
Vitamina C (mg vitamina C/100g) & $16,116 \pm 7,154$ \\
pH & $2,340 \pm 0,020$ \\
\hline
\end{tabular}

Nota. O suco comercial em pó foi usado apenas para comparação.

Fonte: Autores (2021).

Com relação aos sólidos solúveis dos sucos reidratados na Tabela 3 e comparando com os sucos in natura com as concentrações de maltodextrina, antes do processo de secagem Tabela 2. Observa-se uma proximidade desses valores, logo o produto manteve o teor de sólidos solúveis, ou seja, a quantidade de açúcar foi mantida após o processo. Essa explicação pode ser comprovada estatisticamente, em relação ao aumento da temperatura de 140 para $160^{\circ} \mathrm{C}$, para todas as concentrações de maltodextrina não houve diferença estatística $(p>0,05)$ porque a quantidade de sólidos solúveis se manteve praticamente a mesma.

Ao comparar os sólidos solúveis reidratado da Tabela 3 com os sólidos solúveis reidratado do suco comercial em pó da Tabela 4 verifica-se que o suco comercial, preparado conforme indicação da embalagem tem praticamente apenas água e uma pequena quantidade de açúcar, sem qualquer valor nutricional relevante.

Na Tabela 3 mostra a atividade de água obtida para o suco em pó de acordo com os resultados apresentados, esses valores variaram de $0,216 \pm 0,013$ a $0,297 \pm 0,022$. Pode-se notar que a medida que a temperatura do ar de secagem aumenta a atividade de água reduz, devido ao efeito do calor nos produtos secos, portanto embora exista uma variação ela é pequena e desprezivel. Ferrari et al. (2012) também observaram uma diminuição da atividade de água com o aumento da temperatura de 
entrada do ar na secagem. Analisando estatisticamente com relação ao aumento da temperatura do ar de secagem, nas concentrações de 15, 20 e 25\% de maltodextrina, nota-se que a atividade de água, não se altera. $(\mathrm{p}>0,05)$.

As determinações da atividade de água do pós da laranja se encontram abaixo de 0,6. Segundo Quek et al. (2007), alimentos com atividade de água menores que 0,6 são considerados micro biologicamente estável e a ocorrência de deterioração é induzida por reações químicas ao invés de microrganismos.

Com relação a variação da atividade de água causada pelas diferentes concentrações do agente carreador, Quek et al. (2007) observaram uma diminuição da atividade de água com o aumento da concentração de maltodextrina, essa variação pode ser considerada muito pequena e desprezível, em alguns casos que se assemelha ao observado por Ferrari et al. (2012) que obtiveram pós onde a atividade de água não variou com a concentração do agente carreador.

Comparando os resultados da Tabela 3 com o produto comercial apresentado na Tabela 4, observa-se que a atividade do produto comercial se mostra bem mais elevada em relação aos pós-processados na Tabela 3, porém estes sucos possuem aditivos e conservantes que aumentam sua vida de prateleira mesmo com elevada atividade de água.

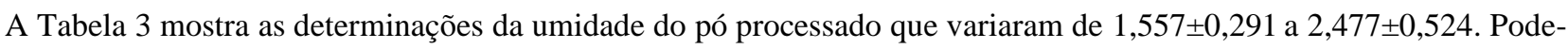
se observer que o aumento da temperatura do ar de secagem reduz o teor da umidade dos pós processados para cada concentração de maltodextrina, novamente devido ao efeito de calor. Analisando estatisticamente os dados da Tabela 3, para cada concentração de maltodextrina, pode-se constatar que de forma geral, o aumento da temperatura do ar de secagem de 140 para $160^{\circ} \mathrm{C}$, não evidencia diferença $(\mathrm{p}>0,05)$.

Comportamento semelhante ao observado por Tonon et al. (2009), que explica esse comportamento devido ao fato de que o uso de temperaturas mais altas implica em uma maior diferença de temperaturas entre o produto atomizado e o ar de secagem, acarretando uma maior transferência de calor e, consequentemente, uma maior evaporação de água do produto, resultando em umidades mais baixas. Com relação a concentração do agente carreador, pode-se observar uma diminuição da umidade com o aumento da quantidade de agente carreador, essa redução vai de 5,45\% a 27,3\% para as diferentes condições. Essa redução da umidade com o aumento da concentração da maltodextrina também é explicado por Quek et al. (2007) onde mais maltodextrina adicionada aumenta o teor de sólidos totais e reduz a quantidade de água para evaporação, reduzindo o teor de umidade. Os valores de umidade apresentados nas Tabelas 3 e 4 se mostram próximos ou até inferiores ao observado na literatura (Tan et al., 2011; Oliveira et al., 2013; Perrone et al., 2013; Santos et al., 2013; Santos et al., 2014; Cavalcante et al., 2017).

Ao comparar a umidade dos pós-processados da Tabela 3 com a umidade do suco em pó comercial da Tabela 4, podese observar que a umidade do pó comercial é menor em relação a umidade dos pós-processados, essa redução pode ser justificada devido a provável diferença no processo de produção.

O teor de umidade representa a água livre e água ligada contido no pó processado e a atividade de água permite avaliar a disponibilidade de água livre que é susceptível a diversas reações. Pode-se observar uma relação, que quando se tem menores valores de atividade de água do pó processado, se tem também menores valores de umidade, conforme esperado.

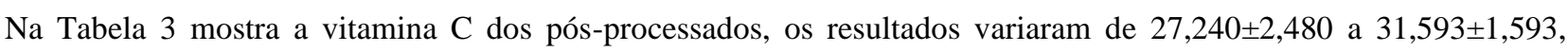
temos que com a mudança na temperatura pouco se observa sua variação. Comparando a vitamina C dos sucos em pó com o suco in natura da laranja da Tabela 2, a perda de vitamina C no processo ficou entre 22 e $30 \%$. Perdas bem menores comparadas ao obtido por Rocha et al. (2014) e Galvão et al. (2016).

Pode-se perceber que, o aumento da concentração do agente carreador e das temperaturas, não interfere estatisticamente na concentração de vitamina $C(p>0,05)$.

Comparando os resultados da vitamina $\mathrm{C}$ dos pós obtidos por spray dryer da Tabela 3 com o resultado da vitamina $\mathrm{C}$ do suco comercial da Tabela 4. As determinações das vitaminas $\mathrm{C}$ do pó processado se encontram bem superior ao resultado da 
vitamina C do produto comercial. Embora inferior o resultado da vitamina C, encontra-se dentro da faixa observada por Silva et al. (2005) na análise do preparo sólido para refresco sabor laranja, onde esse teor variou de 0,67 a $32 \mathrm{mg}$ de ácido ascórbico/100g, assim como os valores para o suco dos pós obtidos estão dentro da faixa de teor de vitamina $\mathrm{C}$ determinado pelo autor para o suco industrial de laranja que apresentou valores de 17,25 a 62,40 mg de ácido ascórbico/100g.

Todos os valores de teor de vitamina $\mathrm{C}$ para os pós obtidos se mostraram superior ao regulamentado segundo a (Instrução Normativa $\mathrm{n}^{\circ} 1,2000$ ) onde para o suco de laranja o teor mínimo de ácido ascórbico deve ser de $25 \mathrm{mg} / 100 \mathrm{~g}$. Além de que o pó obtido pode ser considerado uma boa fonte de vitamina $\mathrm{C}$, visto que a ingestão diária recomendada (IDR) no Brasil, é de 45 mg (Resolução da Diretoria Colegiada - RDC n 272, 2005), logo seria necessário a ingestão de aproximadamente $150 \mathrm{ml}$ do suco produzido por dia para cumprir a recomendação.

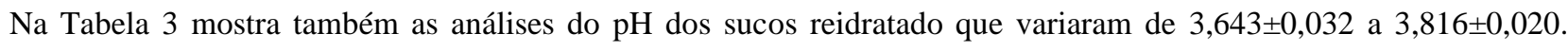
Observa-se que esses valores se mantiveram bem próximos dos valores medidos para o suco in natura da Tabela 2. Os valores se mantiveram aproximadamente os mesmos evidenciando que os ácidos presentes no suco antes do processo de secagem foram conservados em sua grande maioria, o que representa uma vantagem visto que se busca a viabilidade da secagem de um produto visando sua conservação sem a perda de suas propriedades. Avaliando estatisticamente pode-se perceber que não há diferença ( $p>0,05)$, com o aumento da concentração do agente carreador e das temperaturas do ar de secagem.

Os valores obtidos para o pH foram próximos do valor obtido por Rocha et al. (2014) de 3,88 para o suco de caju em pó e próximos aos valores encontrados por (Santos et al., 2014) para o pó de goiaba atomizado de 3,88.

Comparando o $\mathrm{pH}$ da Tabela 2 do suco in natura e suco in natura com percentual de maltodextrina com os $\mathrm{pH}$ dos pós processados da Tabela 3, nota-se que o $\mathrm{pH}$ dos pós processados apresentam superior ao produto comercial da Tabela 4. No entanto, o suco em pó comercial apresentou um pH próximo, porém um pouco menor que os valores obtidos por Silva et al. (2005) para preparo sólido para refresco sabor laranja que teve seus resultados variando de 2,42 a 3,11 para as diferentes marcas do produto.

A Figura 1 podemos observar que os pós obtidos apresentam uma distribuição de partículas larga, onde a faixa onde há a maior porcentagem de partículas entre um diâmetro de aproximadamente 3 a $11 \mu \mathrm{m}$. Um comportamento polimodal, ou seja, com diversos picos de diâmetros é observado. Pode-se observar também que a distribuição de partículas é bem parecida para as diferentes condições de temperatura e de concentração de maltodextrina utilizada, além de que o diâmetro médio de partícula para as diferentes condições de secagem apresenta valores bem próximos como mostra na Tabela 5 , logo a variação na temperatura e na concentração do agente carreador não exerceram influência nos tamanhos das partículas obtidas, o tamanho das partículas sofre grande influencia da pressão e velocidade de atomização pois há modificação no tamanho das micro gotas (Tontul \& Topuz, 2017), e essas variáveis foram mantidas constantes em nossos estudos. Esse comportamento difere do observado por Ferrari et al. (2012), em que eles obtiveram um aumento do diâmetro médio tanto com o aumento da temperatura como com o aumento da concentração de maltodextrina. 
Figura 1. Gráficos da análise granulométrica realizada nos pós obtidos no processo de secagem nas diferentes condições sendo (a) distribuição (b) cumulativo.

(a) Distribuição

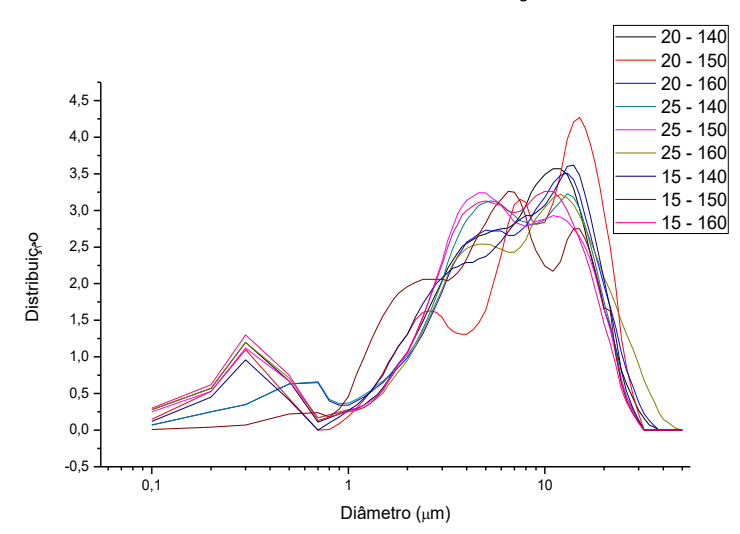

(b) Cumulativo

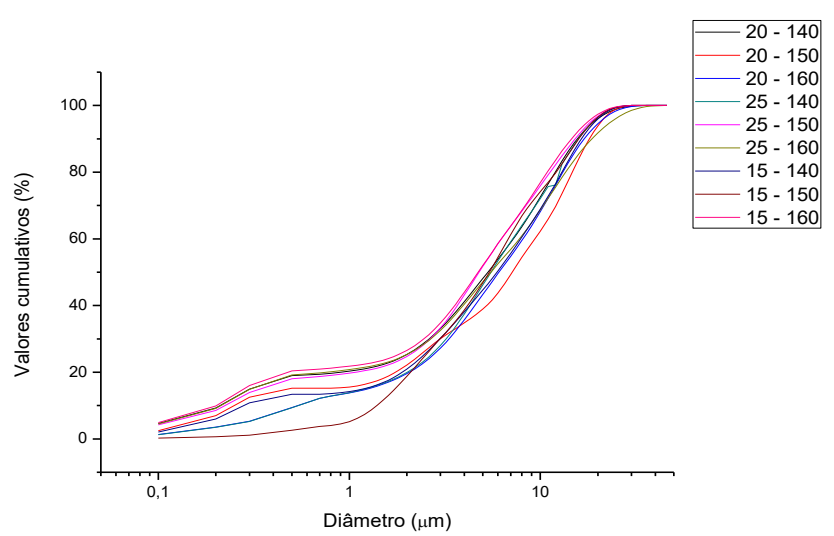

Fonte: Autores (2021).

A Figura 2 mostra que distribuição de partículas do suco em pó comercial é uma distribuição larga, com comportamento polimodal, com vários picos em faixas estreitas em tamanhos diferentes de diâmetro das partículas. Essa grande variação de tamanhos e inúmeros picos pode ser explicado pela presença de inúmeros ingredientes na sua composição, como açúcar, acidulantes, espessantes, conservantes, vitaminas, corantes, etc. que apresentam tamanhos de partículas variados. Além disso, o suco comercial, como observa-se na Tabela 5 apresenta um diâmetro médio ponderado bem mais elevado que o suco em pó obtido nas diferentes condições de secagem que foi de 6,25 a 8,35 $\mu \mathrm{m}$. Segundo Alcantara et al. (2018) observaram

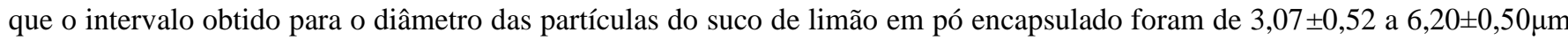

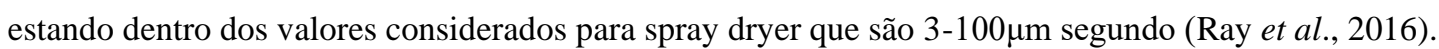

Figura 2. Gráficos da análise granulométrica realizada para o suco comercial em pó e a maltodextrina sendo (a) distribuição e (b) cumulativo.

(a) Distribuição

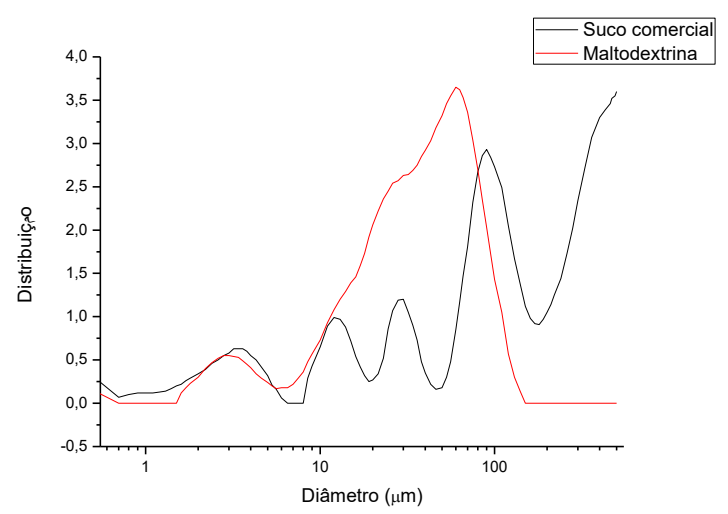

(b) Cumulativo

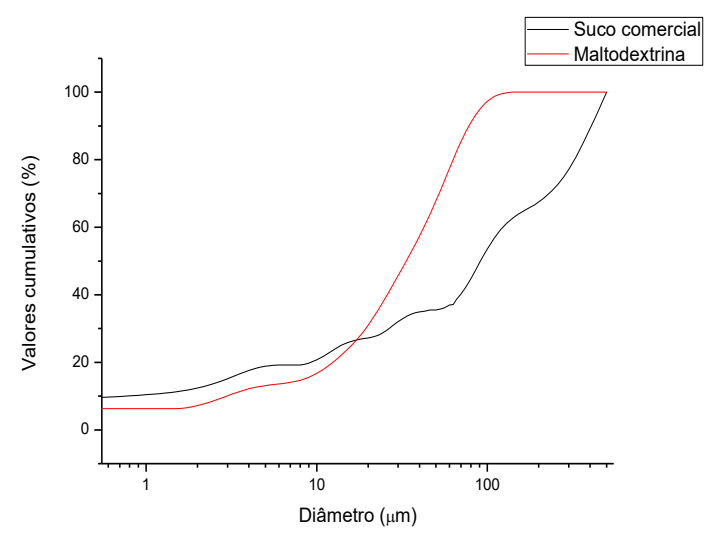

Fonte: Autores (2021). 
A Tabela 5 mostra o diâmetro médio ponderado das análises granulométricas do suco em pó comercial e da maltodextrina pura e dos pós obtidos nas diferentes condições de secagem. O suco comercial apresenta um diâmetro médio ponderado bem mais elevado que o suco em pó obtido nas diferentes condições de secagem que foi de 6,25 a 8,35 $\mu$ m. Segundo Alcantara et al. (2018) observaram que o intervalo obtido para o diâmetro das partículas do suco de limão em pó encapsulado foram de $3,07 \pm 0,52$ a $6,20 \pm 0,50 \mu \mathrm{m}$ estando dentro dos valores considerados para spray dryer que são 3-100 $\mu \mathrm{m}$ segundo (Ray et al., 2016).

Já com relação a maltodextrina pura, tem-se que seu diâmetro médio ponderado é bem mais elevado que os sucos em pós obtidos na Tabela 5, essa diferença se dar provavelmente ao método de produção, porém apresenta uma distribuição parecida, larga e com um comportamento polimodal com três picos de diâmetros predominantes, sendo a faixa de 10 a $100 \mu$ m, uma faixa de tamanho onde há uma porcentagem de partículas predominante.

Tabela 5. Diâmetro médio ponderado das análises granulométricas do suco em pó comercial e da maltodextrina pura e dos pós obtidos nas diferentes condições de secagem.

\begin{tabular}{lc}
\hline Condição de secagem & Diâmetro médio ponderado $(\boldsymbol{\mu m})$ \\
\hline (a) Suco em pó comercial & 151,79 \\
(b) Maltodextrina pura & 38,31 \\
(c) $15 \%$ e $140^{\circ} \mathrm{C}$ & 7,44 \\
(d) $15 \%$ e $150^{\circ} \mathrm{C}$ & 7,09 \\
(e) $15 \%$ e $160^{\circ} \mathrm{C}$ & 6,25 \\
(f) $20 \%$ e $140^{\circ} \mathrm{C}$ & 6,89 \\
(g) $20 \%$ e $150^{\circ} \mathrm{C}$ & 8,35 \\
(h) $20 \%$ e $160^{\circ} \mathrm{C}$ & 7,77 \\
(i) $25 \%$ e $140^{\circ} \mathrm{C}$ & 7,15 \\
(j) $25 \%$ e $150^{\circ} \mathrm{C}$ & 6,46 \\
(l) $25 \%$ e $160^{\circ} \mathrm{C}$ & 7,83 \\
\hline
\end{tabular}

Fonte: Autores.

A Figura 3 mostra a microscopia eletrônica de varredura (MEV) do pó de apenas 1 amostra já que todas apresentam estruturas de tamanhos e morfologia bem similares em todas as diferentes condições de secagem e concentrações de maltodextrina. Essa característica de partículas de diversos tamanhos pode ser observada nas análises granulométricas dos pós obtidos nas diferentes condições de secagem na Tabela 5. A grande maioria das partículas possui tamanhos e formas diferentes com superfície lisa e formato esférico, devido a suspensão das partículas no ar, característico de partículas obtidas após processo de spray dryer, porém pode-se observar a presença de algumas partículas enrugadas, irregulares, encolhidas ou reduzidas e algumas com vazios, devido ao rompimento das partículas durante o processo de secagem. Esse tipo de morfologia observada nas amostras pode ser comparado com o pó obtido por Tonon et al. (2009); por Ferrari et al. (2012); por (Hardy \& Jideane, 2017) e Alcantara et al. (2018). 
Figura 3. MEV para o suco comercial em pó obtido na condição de secagem com 15\% de maltodextrina e temperatura de $140^{\circ} \mathrm{C}$ com aumento de 2000 vezes.

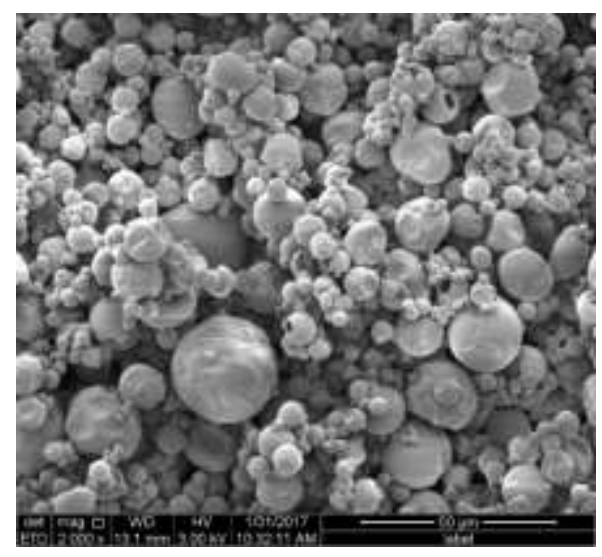

Fonte: Autores.

A Figura 4 mostra a microscopia do suco em pó comercial apresentada na mostra a presença de partículas maiores, possivelmente grãos de açúcar, visto que é o ingrediente predominante na composição desses sucos. Na Figura 4 (c) e (d) observa-se a superfície do grão de açúcar, que apresenta partículas menores aderidas a ele. As imagens obtidas na microscopia eletrônica de varredura confirmam o observado na análise granulométrica, onde tem-se uma distribuição larga e polimodal, ou seja, vários tamanhos de partículas, além de um diâmetro médio bem mais elevado que o suco em pó obtido. Esse tipo de morfologia difere da observada no suco em pó obtido e da morfologia característica de secagem em spray dryer, logo o suco em pó comercial utilizado nesse estudo foi obtido por outro meio de secagem. Pelas imagens do MEV da Figura 4 (a), podemos observar a presença de partículas maiores que $500 \mu \mathrm{m}$ que não aparecem na análise granulométrica devido ao alcance do aparelho. Assim observa uma variação de tamanhos maior ainda que visto na Figura 2 caracterizando mais uma vez a presença de inúmeros ingredientes na sua composição de tamanhos variados. 
Figura 4. MEV para o suco comercial em pó obtido na condição de secagem com $15 \%$ de maltodextrina e temperatura de $140^{\circ} \mathrm{C}$ com aumento de 2000 vezes.

(a)

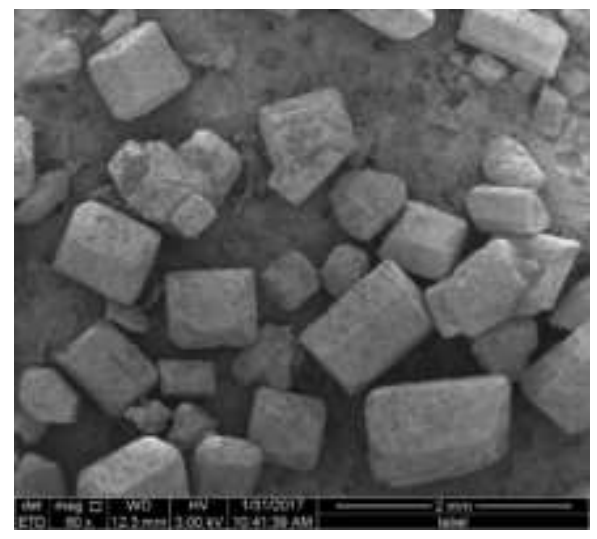

(c)

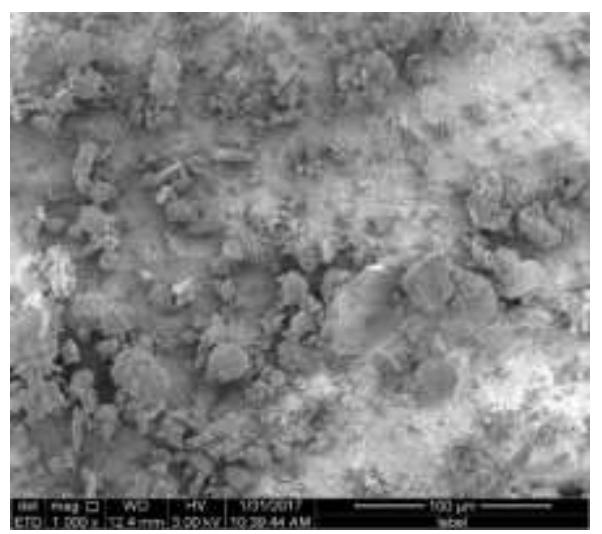

(b)

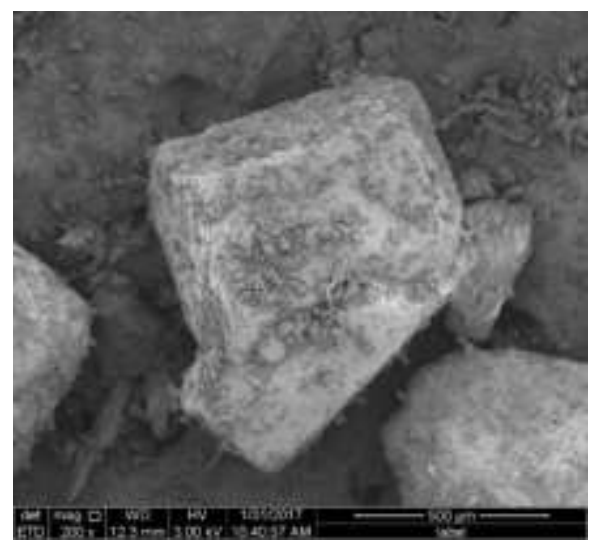

(d)

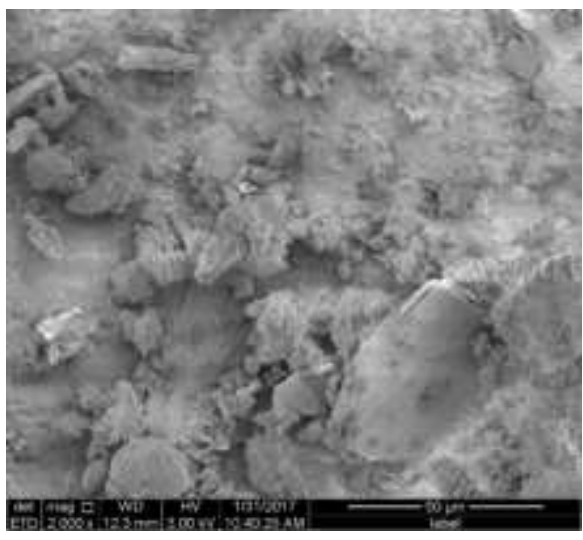

Fonte: Autores.

Na Figura 5 mostra a microscopia eletrônica de varredura da maltodextrina evidencia um pó com partículas de vários tamanhos, predominantemente esférica e a sua superfície é predominantemente lisa com algumas enrugadas. Os autores (Yusraini et al., 2012) observaram que as pequenas partículas de maltodrextrina eram lisas e não apresentavam erosões na superfície exterior das partículas. Esse tipo de morfologia é similar à observada no suco em pó obtido que é característica de pós seco em spray dryer. O trabalho de Silva et al. (2014) confirma esse fato visto que ao falar da produção e caracterização da maltodextrina, cita que usualmente ela é seca em spray dryer para formar um pó branco com $3 \%$ a $5 \%$ de umidade. 
Figura 5. MEV da maltodextrina com aumento de 2000 vezes.

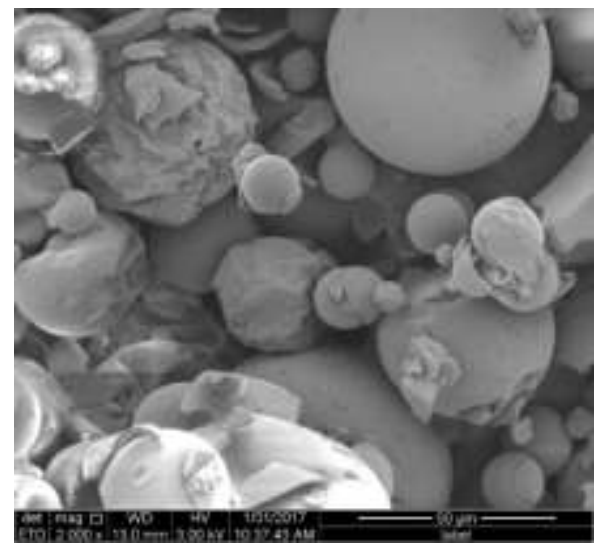

Fonte: Autores.

Os estudos e análises realizados no presente estudo foi patenteado, obtendo a patente BR 1020170201643 de título “Obtenção do suco em pó da laranja (Citrus sinensis) por spray dryer”.

\section{Conclusão}

Após a realização do presente estudo, concluiu-se que foi possível a realização da secagem em spray dryer do suco de laranja com o uso de maltodextrina como agente carreador e nas condições estabelecidas de concentração de 15,20 e $25 \%$ e de temperaturas de entrada do ar de 140,150 e $160^{\circ} \mathrm{C}$. O processo se mostrou viável com rendimentos elevados em torno de $60 \%$. O produto em pó obtido apresentou boas características físico-químicas visto que as propriedades do suco in natura foram conservadas em sua grande maioria, as propriedades relacionadas com a conservação do produto (umidade e atividade de água) apresentaram baixos valores. Além de que sua comparação com o produto comercial similar apresentou uma caracterização físico-química com resultados melhores.

Como sugestões para trabalhos futuros pode-se estudar outras condições de secagem e agentes carreadores, armazenamento, análise granulométrica, avaliação do parâmetro da cor, higroscopicidade, solubilidade, porosidade e densidade que são muito importantes para produtos secos por pulverização.

\section{Referências}

Adhikari, B., Howes, T., Bhandari, B. R., \& Troung, V. (2004). Effect of addition of maltodextrin on drying kinetics and stickiness of sugar and acid-rich foods during convective drying: experiments and modelling. Journal of Food Engineering, 62(1), 53-68. 10.1016/S0260-8774(03)00171-7.

Alcantara M., Berruezo, G. R., Marte, Y. A., \& Tejada, A. E. (2018). Effect of different concentrations of pulverized mesocarp of Citrus paradisi Macf on the morphology and glass transition temperature of spray-dried lemon juice poder. Food Sci Nutr. 6, 1473-1478. 10.1002/fsn3.678.

Amaro, A. A., \& Maia, M. L. (1997). Produção e comércio de laranja e de suco no Brasil. Informações Econômicas, 27(7), 12-4. http://www.iea.sp.gov.br/ftpiea/ie/1997/tec1-0797.pdf.

Aquino, J. de S., da Silva, J. A., de Figuereido, R. M. F., \& de Queiroz, C. M. (2014). Caracterização físico-química e microscópica de ovos desidratados de avestruz. Pesquisa Agropecuária Tropical. 44(4) 468-473. 10.1590/S1983-40632014000400015.

Asquieri, E. R., Nishi, A. C. F., Batista, R. D., \& Asquieri, E. M. A. R. (2020). Yacon extract drying (Smallanthus sonchifolius) by Spray Dryer: effect of the different carrier agents and evaluation of the levels of frutooligosaccharides and phenolic compounds. Research, Society and Development, 9(7): 1-26, e591974521. 10.33448/rsd-v9i7.4521.

Bhandari, B. R., Datta, N., \& Howes, T. (1997). Problems associated with spray drying of sugar-rice foods. Drying Technology, 15(2), 671-684. $10.1080 / 07373939708917253$.

Resolução da Diretoria Colegiada - RDC n 272, de 22 de setembro de 2005. Dispõe sobre o "Regulamento Técnico para produtos de vegetais, produtos de frutas e cogumelos comestíveis". http://bvsms.saude.gov.br/bvs/saudelegis/anvisa/2005/rdc0272_22_09_2005.html. 
Instrução Normativa ${ }^{\circ}$ 1, de 07 de janeiro de 2000. Dispõe sobre o "Regulamento Técnico Geral para fixação dos Padrões de Identidade e Qualidade para Polpa de Fruta".

Cavalcante, C. E. B., Rodrigues, S., Afonso, M. R. A., \& Costa, J. M. C. (2017). Avaliação dos parâmetros de secagem da polpa de graviola em pó obtida por secagem em spray dryer. Brazilian Journal of Food Technology, 20, e2016015. 10.1590/1981-6723.1516.

Chegini, G. R., \& Ghobadian, B. (2007). Spray dryer parameters for fruit juice drying. World Journal of Agricultural Sciences, 3(2), $230-236$. http://www.idosi.org/wjas/wjas3(2)/14.pdf.

Couto, M. A. L., \& Canniatti-brazaca, S. G. (2010). Quantificação de vitamina C e capacidade antioxidante de variedades cítricas. Ciência e Tecnologia de Alimentos 30(Supl.1), 15-19. https://www.scielo.br/pdf/cta/v30s1/03.pdf.

Corrêa Neto, R. da S., Faria, J. de A. F. (1999). Fatores que influem na qualidade do suco de laranja. Ciência e Tecnologia de Alimentos. 19(1), 153-161. $10.1590 / \mathrm{S} 0101-20611999000100028$.

Cunha, K. D., Silva, P. R., Costa, A. L. F. S. F., \& Teodoro, A. J. (2014). Estabilidade de ácido ascórbico em sucos de frutas frescos sob diferentes formas de armazenamento. Brazilian Journal of Food Technology, Campinas, 17(2), 139-145. https://www.scielo.br/pdf/bjtt/v17n2/a06v17n2.pdf. 10.1590/bjft.2014.016.

Danieli, F., Costa, L. R. L. G. da, Silva, L. C., Hara, A. S. S., \& Silva, A. A. da. (2009). Determinação de vitamina C em amostras de suco de laranja in natura e amostras comerciais de suco de laranja pasteurizado e envasado em embalagem Tetra Pak. J. Rev Inst Ciênc Saúde,27(4), 361-365. http://files.bvs.br/upload/S/0104-1894/2009/v27n4/a1634.pdf.

Fazaeli, M., Emam-Djomeh, Z., Kalbasi Ashtari, A., \& Omid, M. (2012). Effect of spray drying conditions and feed composition on the physical properties of black mulberry juice powder. Food and bioproducts processing, 90(4), 667-675. 10.1016/j.fbp.2012.04.006.

Ferrari, C. C., Ribeiro, C.P., \& Aguirre, J. M. (2012) Secagem por atomização de polpa de amora-preta usando maltodextrina como agente carreador. Brazilian Journal of Food Technology, 15(2), 157-165. https://www.scielo.br/pdf/bjft/v15n2/aop_1411.pdf.

Fioreze, R. (2003). Princípios de Secagem de produtos biológicos: Editora Universitária.

Galvão, L. M. V., Sousa, M. M., Diniz, E. F. C., Silva, O. A., \& Nunes, L. C. C. (2016, Outubro). Análise dos parâmetros físico-químicos de cajuína e cajuína obtido por spray dryer. Congresso Brasileiro de Ciência e Tecnologia de Alimentos, Gramado, RS, Brasil, 25. https://docplayer.com.br/82367551-Analise-dosparametros-fisico-quimicos-de-cajuina-e-cajuina-obtido-por-spray-dryer.html.

Gava, A. J. (1978). Princípios de tecnologia de alimentos. Nobel.

Goula, A. M., \& Adamopoulos, K. G. (2003). Spray drying performance of a laboratory spray dryer for tomato powder preparation. Drying Technology, 21(7), 1273-1289. 10.1081/DRT-120023180.

Gupta, A. S. (1978). Spray drying of orange juice. US Patent 4.112.130 A.

Hardy, Z., \& Jideani, V. A. (2017). Effect of spray drying compartment and maltodextrin concentration on the functional, physical, thermal, and nutritional characteristics of Bambara groundnut milk powder. Journal of Food Processing and Preservetion.e13491. 10.1111/jfpp.13491.

Instituto Adolfo Lutz. (2008). Métodos Físico-Químicos para Análise de Alimentos, (4a ed.).

Instituto Adolfo Lutz. (1985). Normas analíticas do Instituto Adolfo Lutz: métodos químicos e físicos para análise de alimentos. (3a ed.).

Mendoza-Corvis, F. A., Arteaga, M. M., \& Pérez S. O. (2016). Comportamiento de la vitamina C en um producto a base de lactosuero y pulpa de mangovariedad Magdalena River (Mangífera Indica l.) durante el secado por aspersión. Rev Chil Nutr. 43(2), 159-166. https://scielo.conicyt.cl/pdf/rchnut/v43n2/art08.pdf.

Muzaffar, K., Nayik, G. A., \& Kumar, P. (2015). Stickiness problem associated with spray drying of sugar and acid rich foods: a mini review. Journal of Nutrition \& Food Sciences, S12-003, 1. 10.4172/2155-9600.1000S12003.

Oliveira, F. M. N., de Figueirêdo, R. M. F., \& Queiroz, A. J. de M. (2006). Análise comparativa de polpas de pitanga integral, formulada e em pó. Revista Brasileira de Produtos Agroindustriais, 8(1), 25-33. 10.15871/1517-8595/rbpa.v8n1p25-33.

Oliveira, A. R. G., Borges, S. V., Faria, R. K. Endo, E., \& Gregório, S. R. (2007). Influência das condições de secagem por atomização sobre as características sensoriais de sucos maracujá (passiflora edullis) e abacaxi (ananas comosus) desidratados. Revista Ciências Agronômicas, 38(3), 251-256. https://www.redalyc.org/pdf/1953/195317584003.pdf.

Oliveira, M. I. S., Tonon, R. V., Nogueira, R. I., \& Cabral, L. M. C. (2013) Estabilidade da polpa de morango atomizada utilizando diferentes agentes carreadores. Brazilian Journal of Food Technology, 16(4), 310-318. 10.1590/S1981-67232013005000037.

Pereira, A. S., Shitsuka, D. M., Parreira, F. J., \& Shitsuka, R. (2018). Metodologia da pesquisa científica. UFSM. https://repositorio.ufsm.br/bitstream/han dle/1/15824/Lic_Computacao_Metodologia-Pesquisa-Cientifica.pdf?sequence=1.

Perrone, Í. T., Simeão, M., Júnior, P. H. R., Stephani, R., \& de Carvalho, A. F. (2013). Influência das condições de operação em spray dryer piloto sobre a umidade e a atividade de água do leite em pó integral. Revista do Instituto de Laticínios Cândido Tostes,68(393), 5-9. https://www.revistadoilct.com.br/rilct/article/view/30/34.

Phisut, N. (2012). Spray drying technique of fruit juice powder: some factors influencing the properties of product. International Food Research Journal, 19(4), 1297-1306. http://www.ifrj.upm.edu.my/19\%20(04)\%202012/2\%20IFRJ\%2019\%20(04)\%202012\%20Phisut\%20(006).pdf. 
Research, Society and Development, v. 10, n. 2, e49410212739, 2021

(CC BY 4.0) | ISSN 2525-3409 | DOI: http://dx.doi.org/10.33448/rsd-v10i2.12739

Quek, S. Y., Chok, N. K., \& Swedlund, P. (2007). The physicochemical properties of spray-dried watermelon powders. Chemical Engineering and Processing: Process Intensification, 46(5), 386-392. 10.1016/j.cep.2006.06.020.

Ray, S., Raychaudhuri, U., \& Chakraborty, R. (2016). An overview of encapsulation of active compounds used in food products by drying technology. Food Bioscience, 13(1), 76-83. 10.1016/J.FBIO.2015.12.009.

Rocha, É. M., Sousa, S. L., da Costa, J. D. P., Rodrigues, S., Afonso, M. R., \& da Costa, J. (2014). Obtenção de suco de caju atomizado através do controle das condições de secagem. Revista Brasileira de Engenharia Agricola e Ambiental-Agriambi, 18(6), 646-651. 10.1590/S1415-43662014000600012.

Santos, R. M. D., Nääs, I. D. A., Mollo Neto, M., \& Vendrametto, O. (2013). An overview on the Brazilian orange juice production chain. Revista Brasileira de Fruticultura, 35(1), 218-225. 10.1590/S0100-29452013000100025.

Santos, A. A. C., Florêncio, A. K. G. D, Rocha, E. M. de F. F., \& da Costa, J. M. C. (2014) Avaliação físico-química e comportamento higroscópico de goiaba em pó obtida por spray-dryer. Revista Ciência Agronômica, 45(3), 508-514. 10.1590/\$1806-66902014000300010.

Silva, M. V., Junior, B. D., \& Visentainer, J. V. (2014). Produção e caracterização de maltodextrinas e sua aplicação na microencapsulação de compostos alimentícios por spray drying. RECEN-Revista Ciências Exatas e Naturais, 16(1), 111-126. https://revistas.unicentro.br/in dex.php/RECEN/article/view/2882/2355.

Silva, P. T., Fialho, E., Lopes, M. L. M., \& Valente-Mesquita, V. L. (2005). Sucos de laranja industrializados e preparados sólidos para refrescos: estabilidade química e físico-química. Ciência e Tecnologia de Alimentos, 25(3), 597-602. 10.1590/S0101-20612005000300033.

Sugai, A. Y., Shigeoka, D. S., Badolato, G. G., \& Tadini, C. C. (2002). Análise físico-química e microbiológica do suco de laranja minimamente processado armazenado em lata de alumínio. Ciência e Tecnologia de Alimentos, 22(3), 233-238. 10.1590/S0101-20612002000300006.

Tan, L. W., Ibrahim, M. N., Kamil, R., \& Taip, F. S. (2011). Empirical modeling for spray drying process of sticky and non-sticky products. Procedia Food Science, 1, 690-697. 10.1016/j.profoo.2011.09.104.

Tonon, R. V., Baroni, A. F., Barbet, C., Gibert, O., Pallet, D., \& Hubinger, M. D. (2009). Water sorption and glass transition temperature of spray dried açai (Euterpe oleracea Mart.) juice. Journal of Food Engineering, 94(3/4), 215-221. 10.1016/j.jfoodeng.2009.03.009.

Tontul, I., \& Topuz, A. (2017) Spray-drying of fruit and vegetable juices: Effect of drying conditions on the product yield and physical properties. Trends in Food Science \& Technology, 63, 91-102. 10.1016/j.tifs.2017.03.009.

Vasconcelos, E. A. F., Medeiros, M. G. F., Raffin, F. N., \& Moura, T. F. A. L. (2005). Influência da temperatura de secagem e da concentração de Aerosilß 200 nas características dos extratos secos por aspersão da Schinus terebinthifolius Raddi (Anacardiaceae). Revista Brasileira de Farmacognosia, 15(3), 243249. 10.1590/S0102-695X2005000300015.

Yusraini, E., Hariyadi, P., \& Kusnandar, F. (2012). Preparation and partial characterization of low dextrose equivalent (DE) maltodextrin from banana starch produced by enzymatic hydrolysis. Starch/Starke, 65(3-4), 312-321. 10.1002/star.201200080. 